\title{
A validação do tecnobrega no contexto dos novos processos de circulação cultural
}

\section{Lydia Gomes de Barros}

Graduada em Jornalismo pela Universidade Católica de Pernambuco, com mestrado e doutorado em Comunicação e Cultura pela Universidade Federal de Pernambuco (UFPE), e estágio de doutoramento na McGill University (Montreal). Editora do portal de notícias do jornal Diario de Pernambuco.

Email: Iydia_barros@hotmail.com
Resumo: Este artigo aponta a emergência de um novo paradigma de legitimação da música popular brasileira, baseado no aumento da circulação do acervo musical produzido globalmente e na acessibilidade às ferramentas tecnológicas que possibilitam autonomia de criação e de distribuição. Essa hipótese é defendida com base na análise do circuito paraense do tecnobrega, estilo musical que atualiza com recursos da música eletrônica uma tradição musical desprezada pelas elites: a música brega romântica do Pará produzida entre as décadas de 1980 e 1990, que introduziu a informalidade no negócio da música no país.

Palavras-chave: Tecnobrega; Legitimação musical; Circulação; Tecnologia.

Title: The tecnobrega's validation on the new paradigma of cultural circulation

Abstract: This paper intends to show the rise of a new paradigma of the Brazilian popular music legitimation, based on the circulation increase of the musical repertory globally produced and on the accessibility to the technological tools which provides autonomy of creation and distribution. This hypothesis is defended based on the analysis of the tecnobrega scene from Pará (Brazil), musical style that updates with resources from electronic music a musical tradition despised by the elites: the kitsch romantic music from Pará produced between the decades of 1980 and 1990, which introduced the informality in the Brazilian music business.

Keywords: Tecnobrega; Musical legitimation, Circulation, Technology. 


\section{Introdução}

Por sua especificidade geográfica, a cidade de Belém, capital do estado do Pará, região Norte do Brasil, acostumou-se a ser embalada pelos ritmos "calientes" do Caribe que as programações das rádios locais traziam antes mesmo dos sucessos populares nacionais. Talvez por isso mesmo a musicalidade em Belém seja de fronteiras: o pop do mundo tem lugar cativo, ao lado das tradições musicais de raiz (as guitarradas são um clássico) e do cancioneiro romântico popular, sempre bem acolhido pelos moradores da periferia paraense, frequentadores assíduos do circuito de bailes itinerantes da Região Metropolitana da cidade: as aparelhagens. De maneira geral, as aparelhagens, fundamentais para o circuito do tecnobrega analisado neste capítulo, podem ser descritas como empresas familiares que possuem equipamento de som para produzir festas bregas em todo o estado, carregando cabine de controle, torres de caixas de som, telões e equipamentos de efeitos especiais, além de DJs e funcionários que cuidam da montagem e operação dos dispositivos técnicos (LEMOS; CASTRO, 2008).

O tecnobrega surgiu no verão de 2002, mas ainda é uma novidade como fenômeno cultural da capital paraense. Essa música conforma a ideia do novo em pelo menos dois sentidos: primeiro, trata-se de um estilo que descende da música brega romântica, e que era, há até pouco tempo, ignorado pelo público de classe média, seja pela qualidade técnica das gravações, seja pelas letras com apelo de duplo sentido. Uma música que, nas palavras da cantora e líder da banda TecnoShow, Gaby Amarantos, "apelando para baixarias, era discriminada como sendo de periferia, de pobre, e, por isso, não fazia sucesso". Ao optar pelo tema das aparelhagens - o universo autorreferente das festas, dos artistas, DJs e fã-clubes - o tecnobrega parece ter quebrado uma primeira barreira de ordem ideológica, amplificando o seu canal de comunicação para além de círculos menos estigmatizados socialmente.

Essa cena musical também pode ser encarada como novidade, principalmente porque lançou luz sobre a inventividade de um circuito de produção e circulação que se mantém na informalidade, e cuja relativa autonomia agrega capital simbólico à renovação de uma tradição musical periférica que utiliza a tecnologia como sua principal ferramenta. É importante notar que, embora o marco fundador dessa cena tenha sido o verão de 2002, quando os primeiros hits começaram a ser pedidos pelo público nas festas de aparelhagens, somente a partir de 2003, com a entrada em cena da pirataria, o tecnobrega iniciou a sua expansão como fenômeno cultural de massa paralelo, beneficiando-se de novas redes de relacionamento e do comércio informal de discos.

Destaca-se que é preciso considerar a cena musical da cidade, isto é, a existência de um circuito brega local anterior e os processos de fertilização e renovação que impactaram sua longevidade; os mecanismos de diferenciação decorrentes da coexistência de várias práticas musicais; as alianças e formas de comunicação estabelecidas no interior desse circuito; e a relação dessas práticas musicais com a cultura musical internacional (STRAW, 1991). No entanto, é o tecnobrega em sua versão $100 \%$ eletrônica que introduz efetivamente novos elementos à dinâmica de produção, circulação e valoração dessa matriz musical.

Graças ao aporte da tecnologia majoritariamente precária na composição musical, os artistas reduzem os custos de produção de CDs, abrindo caminho para que a maioria das bandas montem estúdios próprios que se transformam em fábricas caseiras de discos. Além disso, ao abrir mão do dinheiro tradicionalmente arrecadado com as vendas dos discos - no caso, doados aos distribuidores informais, que os repassam aos "camelôs-pirateiros", às rádios e às aparelhagens - esses agentes colocam em operação uma indústria de música informal que independe dos humores do mercado institucional. Nessa cadeia produtiva, há uma inversão operacional/conceitual em relação à indústria fonográfica formal, 
já que, antes de gravarem seus próprios CDs, as bandas já foram "testadas" nas coletâneas que os DJs fazem chegar às ruas.

Com batidas eletrônicas de bateria, efeitos sonoros e samplers baixados da internet (os programas mais utilizados no início eram o Soundforge e o Vegas) ou pirateados de jogos eletrônicos como Mortal Kombat e Street Fighter, o tecnobrega surge como promessa de modernização da tradição brega local, criando novas sonoridades para gêneros regionais como o flash brega e o bregacalipso, com a pegada da música eletrônica global. Dessa forma, o tecnobrega se afirma como tradução atualizada da música pop mundial recente, a qual atua simultaneamente como barreira à circulação do pop em suas formas originais e agente de sua propagação, com base em recriações e apropriações. Não por acaso, essa música é uma expressão que traduz um pensamento estético da periferia de Belém de forma territorializada, no sentido dos estilos de vida e influências culturais dos quais emana, mas ainda assim sintonizada com a produção musical global.

Observa-se o tecnobrega aqui no contexto do que a pesquisadora Simone de Sá Pereira chama de "música eletrônica popular brasileira" (PEREIRA DE SÁ, 2008), já que sua criação tem como base as apropriações tecnológicas e a utilização do acervo de sons disponibilizados pela internet inspirada em informações sonoras transnacionais, ainda que a criação de ritmos e timbres, nesse caso, seja fortemente marcada pelos localismos. Entre as principais recorrências nessa expressão da matriz eletrônica mundial figuram a mistura da música disco com a bateria eletrônica (o house), que é intensificada pela marcação acelerada definida como "bate-estaca", a exploração da potência máxima do som para o ambiente das festas e o acionamento de um circuito de produção/circulação independentes.

Segundo levantamento da Fundação Getúlio Vargas (FGV), são produzidas em torno de 3.200 aparelhagens mensalmente em Belém. As festas mais populares costumam reunir um público de 10 a 15 mil pessoas por noite, embora a preferência dos frequentadores desse circuito mude em função das novidades tecnológicas anunciadas pelas produções. No final de 2010, por exemplo, Rubi, Super Pop (Águia de Fogo), Tupinambá, Brasilândia e Príncipe Negro, estavam entre as aparelhagens mais prestigiadas de Belém, mas, no momento da publicação deste trabalho, podem ter perdido a sua força. É fato, no entanto, que as chamadas grandes aparelhagens, as quais possuem maior volume de equipamentos, conseguem se reciclar rapidamente e disputar o público com mais autonomia.

Se a tecnologia é o alimento dessa cena musical, a pirataria é o seu motor. É graças a ela que bandas e DJs mantêm a popularidade em alta em todo estado do Pará, ainda que boa parte desses artistas nunca tenha se apresentado em muitos dos recônditos da região onde têm fama. É também graças a ela que o tecnobrega ganha terreno nos estados vizinhos, "importando", inclusive, seu modelo de festa. Para se ter uma ideia, as aparelhagens realizadas em Macapá seguem a mesma lógica das paraenses, embora com menos tecnologia; no Maranhão, as aparelhagens (chamadas "radiolas") tocam reggae e são produzidas com tecnologia paraense (os suportes dos equipamentos são confeccionados por carpinteiros de Belém). É a pirataria, ainda, que viabiliza um nicho de mercado paralelo, os DVDs, cuja produção vem abrindo novos postos de trabalho e garantindo um novo fôlego à cena. Foi também a pirataria que assegurou a completa inserção dessa música nos meios de comunicação de massa da cidade.

As bandas gravavam os CDs nos seus estúdios, encapavam o disquinho e traziam para mim. Eu tocava no meu programa numa rádio comunitária, levava para as aparelhagens, que mandavam para a pirataria. Assim, derrubamos o jabá em Belém. Tinha rádio aqui que não tocava brega nem pagando, e hoje tem o tecnobrega em sua programação diária. Se você ouvir 30 minutos da programação da Rádio Liberal, que é a rádio classe $A$ de Belém, dez é de 
${ }^{1}$ Entrevista concedida por Dj Metralha. [08 março de 2008]. Entrevistadora: Lydia Barros. Pará/Brasil. tecnobrega. Foi um trabalho de formiguinha. A mídia ignorando e a gente se espalhando de uma forma muita rápida. Não teve como segurar a gente. Os pirateiros dão uma força que você nem imagina. Se o cara faz uma música que cai no gosto da galera, essa música chega ao estado inteiro, sem você mandar nem um CD para lá. (informação verbal) ${ }^{1}$

Ronaldo Lemos e Oana Castro (2008) entendem que o mercado do tecnobrega, ainda que estruturado em redes e atributos locais, serve de importante referência global à produção de bens culturais. Ressaltam que a hipótese do projeto Open Business Latin America é de que a apropriação de tecnologias de produção musical de baixo custo, aliada à flexibilização do direito de propriedade intelectual, possibilita a formação de mercados culturais tão ou mais viáveis dos que os modelos usuais. "Mercados estes que têm um grande potencial inclusivo, por garantirem amplo acesso à produção" (2008, p. 23). Note-se que a música é o meio de vida para artistas e produtores do tecnobrega, em sua maioria "empresários" deles mesmos, e, ainda, oportunidade de renda para a família e amigos, que acabam absorvendo um conhecimento técnico necessário à atuação nesses mercados musicais, e integrando a importante network que os mantém em operação.

É importante enfatizar, no entanto, que, se o caráter emancipador dessa produção musical se materializa no volume de canções que chegam ao mercado semanalmente, garantindo o dinamismo interno da cena, ele se fragiliza no que diz respeito à saturação desse mercado e na sua relação com a indústria musical institucional. Além disso, apesar das facilidades da produção do tecnobrega nos estúdios, geralmente ambientados em algum cômodo da casa do produtor/DJ, o dia a dia desses agentes costuma ser estressante na medida em que várias demandas precisam ser atendidas quase que simultaneamente. Paulo Murilo Guerreiro do Amaral (2009) explica que a necessidade de produzir muitos hits em pouco tempo coloca em tensão duas realidades do cotidiano desses profissionais: o anonimato do seu ofício e o reduzido número de músicas que efetivamente emplacam nas paradas de sucesso das aparelhagens e nos repertórios das bandas de tecnobrega.

\section{Uma periferia digitalizada}

Não se pode pensar a invenção do tecnobrega sem considerar o fluxo das mercadorias culturais globalizadas, a velocidade das apropriações de produtos e bens simbólicos, e os processos de hibridização e circularidade que marcam os artefatos culturais contemporâneos. Não por acaso, é possível perceber interseções entre expressões musicais como o tecnobrega, o rap e o funk, todas elas protagonizadas por jovens atores das periferias urbanas, seduzidos pela cultura pop mainstream; filhos de uma sociedade "canibal do mundo desenvolvido, criativamente despudorada em seus problemas com a lei e festiva" (PEREIRA DE SÁ, 2008, p. 4). Para Guerreiro do Amaral, o tecnobrega é uma expressão do cosmopolitismo, em termos de tempos e espaços entrecruzados, que se reflete em comportamentos, práticas culturais e discurso sonoro:

A utilização de recursos computacionais na produção do tecnobrega me leva a crer que a música se encontra muito bem relacionada com tecnologias disponíveis no mercado mundial (desde equipamentos de som até softwares para manipulação musical), como também produtores e outros personagens desta cena musical deixam claro o desejo de que ela se mantenha sempre atualizada, ou seja, que reflita linguagens contemporâneas e universais presentes na música massiva global. (GUERREIRO DO AMARAL, 2009, p. 17)

Um dos pioneiros da cena tecnobrega, ainda hoje atuante, o DJ e produtor Beto Metralha afirma que aprendeu a manipular programas de computador sozinho, pois tinha consciência de que essa seria a forma de estar em conexão com o mundo. 
${ }^{2}$ Entrevista concedida por Dj Metralha. [08 março, 2008]. Entrevistadora: Lydia Barros. Pará/Brasil.

\footnotetext{
${ }^{3}$ Entrevista concedida por Dj Metralha. [08 março de 2008]. Entrevistadora: Lydia Barros. Pará/Brasil.
}

${ }^{4}$ Cf. BARROS, 2011, p. 29.
“Em Belém, só se sabe das coisas pela internet, não tem curso de nada, é preciso estar por conta própria" (informação verbal)². O DJ/produtor conta que trabalhava na criação de jingles publicitários, atividade que conciliava com a de DJ nas boates de Belém, razão pela qual costumava manipular, no estúdio improvisado em sua casa no bairro do Jurunas, um programa de bateria eletrônica sobre o qual criou suas primeiras versões do tecnobrega, inspirado no house que programava.

Como foi isso? Fiz um sampler da batida que criei, botei na trilha e fui pegando os solos do house que estavam na moda. Falei: a gente vai pegar essa melodia brega e tentar chegar o mais próximo possível desse solo aqui, mas jogando ele com o tecnobrega. Ai o pessoal pirava, porque já tinha assimilado aquela música de outra forma. Como o brega não era o tal da hora, as pessoas falavam: puxa, esse cara fez um brega daquela música tal, e assim foi. (informação verbal) ${ }^{3}$

Segundo Gaby Amarantos, o "eletro-ritmo", criado no teclado eletrônico como base para os demais instrumentos, representou uma economia para as bandas da ordem de $80 \%$ - "gastava-se, em média, R\$ 3 a R\$ 4 mil para gravar uma música; era inviável" (informação verbal) ${ }^{4}$. A cantora ressalta que, a partir daí, DJs como Jurandir, Beto Metralha e Iran, entre outros, foram criando sonoridades no computador, "sampleando" as batidas eletrônicas e criando ritmos diferentes, mais tarde identificados genericamente como tecnobrega.

São mesmo muitas as subdivisões do tecnobrega, embora o ouvinte forasteiro possa não perceber as variações que o estilo sofre. Isso porque, mesmo que todos os estilos do tecnobrega sejam tocados em uma festa de aparelhagem, o que menos se escuta é a música propriamente dita, já que as atenções estão voltadas para os DJs que comandam, falam, mandam recados, abraços e aproveitam para vender CDs piratas mixados na ocasião. A estratégia é simples: se um frequentador escuta seu nome ser citado pelo DJ, provavelmente vai comprar alguns CDs para distribuir entre os amigos, mostrar que seu nome foi citado e o seu "prestígio" naquela aparelhagem. Dezenas de nomes saem das caixas de som; centenas de CDs são vendidos ali mesmo.

Para Ronaldo Lemos e Oana Castro (2008), vários fatores contribuíram para a conquista de espaços e público pelo tecnobrega, entre os quais estão a melhora na produção dos CDs e DVDs, a realização de shows em feriados importantes no interior do Pará (que arregimentaram grandes plateias), a criação de programas de rádio pelos artistas da cena e a exposição na mídia eletrônica (LEMOS; CASTRO, 2008). Mas, diferentemente da posição defendida por esses autores, para quem a entrada dessa música nos meios de comunicação de massa não determinou o sucesso do tecnobrega (a conquista do público massivo teria imposto a esses meios a sua assimilação), entende-se que, embora o fenômeno já houvesse conquistado ouvintes das regiões Norte e Nordeste do Brasil, o capital cultural (BOURDIEU, 2006) de intermediadores de grande apelo midiático emprestou novo status à música produzida no Pará.

Afinal, é importante não perder de vista que a eficácia dos nichos de produção cultural periféricos, paralelos às indústrias culturais centrais, muitas vezes é resultado de estratégias que visam ao caminho da inserção, material ou simbólica, na cultura institucional. Não há mais, é verdade, a necessidade do aval da crítica ou das gravadoras para que essa música chegue ao mercado. Mas devese observar, no caso do tecnobrega, que foram intermediadores como a atriz e produtora Regina Casé e o antropólogo Hermano Vianna que contribuíram para a legitimação dessa cena para além das regiões Norte e Nordeste do Brasil, a partir da exibição do programa Central da Periferia, na Rede Globo de Televisão.

Como herdeiro de uma tradição musical que cristaliza distinções culturais socialmente construídas e cuja expressão semântica (brega), segundo Samuel 
Araújo, "mantém incorporado um aspecto depreciativo, não importando os significados que traga consigo" (1987 apud GUERREIRO DO AMARAL, 2009, p. 21), o tecnobrega parece encontrar na sua lógica de produção a explicação mais óbvia para a sua validação estética, lógica mais próxima da produção independente legitimada pelos formadores de opinião e hoje incorporada por outras cenas musicais periféricas do país (como o próprio funk e o rap).

Defende-se aqui que, na base dessa validação, repousa o interesse pelos novos nichos de mercado abertos com a difusão das novas tecnologias e a preocupação com o impacto dessas mudanças nas indústrias culturais formais. De maneira mais abrangente, entende-se que o atual debate público sobre a cultura periférica está centrado nos modelos de negócio que viabilizam a sua produção e circulação, ou mais precisamente e na linguagem corrente, nas culturas digitalizadas. Deve-se lembrar, nesse sentido, que a popularização do tecnobrega opera uma mudança do referente de construção de valor da música brega, historicamente associada às ideologias de classe, e, consequentemente, ao que é considerado vulgar e de mau gosto.

Dessa forma, além da adesão do seu público tradicional, o tecnobrega conquista a simpatia de uma elite cultural que reconhece a importância dos novos modelos de negócio praticados pelas periferias ao redor do mundo colocando em xeque, assim como o fazem fenômenos musicais como o kuduro em Angola, o kwaito na África do Sul e o bubblin em Suriname, a própria ideia de inclusão. Experiências que encontram eco em uma das argumentações mais pertinentes do antropólogo Hermano Vianna:

Quando falamos de inclusão, partimos geralmente da suposição de que o centro (incluído) tem aquilo que falta à periferia (que precisa ser incluída). É como se a periferia não tivesse cultura, tecnologia ou economia. É como se a periferia fosse um dia ter (ou como se a periferia almejasse ter, ou será melhor que tivesse) aquilo que o centro já tem (e por isso pode ensinar a periferia como chegar lá, para o bem da periferia). É como se as novidades tecnológicas ou culturais chegassem exclusivamente pelo centro, ou fossem criadas no centro, e lentamente se espalhassem - à custa de muito esforço civilizatório - em direção à periferia [...]. Sem que o centro nem notasse, [a periferia] inventou culturas digitalizadas que podem muito bem vir a indicar caminhos para o futuro do centro, que não parece conseguir desenvolver por si próprio nenhum "plano de negócio" consistente para lidar com a nova realidade tecnológica. (2006, p. 2)

A posivitação dos processos de apropriação tecnológica por sujeitos socialmente excluídos compreende, ainda, o reconhecimento da importância dos processos criativos como prática cotidiana, espaço de interação e construção de valor, considerando a textura social das produções culturais e o diálogo que as mesmas estabelecem entre si. Na hipótese de mudança do paradigma de validação da crítica musical brasileira, defendida neste trabalho, tal pressuposto encontra um lastro conceitual no que Dilip Gaonkar e Elizabeth Povinelli entendem como "culturas da circulação" (2003), que evidenciam a transformação da criatividade em um ativo econômico que impacta decisivamente nas formas de apreensão das formas culturais, sejam elas periféricas ou não.

\section{Circulação cultural: novos processos sociais}

O debate em torno da questão da criatividade nos processos produtivos, como lembram os canadenses Massumi e Manning (s.d.), vem mobilizando esforços multidisciplinares em torno de uma "ética da invenção", termo que esses autores tomam de empréstimo de Félix Guattari (1995) para falar sobre a capacidade de a arte produzir alteridade, subjetividades e múltiplas noções da diferença. Para os autores, os processos de produção estão se tornando produtos em si; consumidores não consomem apenas objetos, mas ativas plataformas de 
produtividade criativa. Essas plataformas, argumentam os autores, geralmente se expandem em matrizes baseadas em grupos de afinidades no interior dos quais novas práticas de expressão, por meio das quais os sujeitos se reconhecem, são desenvolvidas. A referência à "invenção", no trabalho de Massumi e Manning, remete à questão da tecnologia, sobretudo às mídias digitais, e à materialidade de bens imateriais. Para eles, a noção contemporânea de concreto não é mais objetiva, mas interativa, ainda que essa interatividade seja manipulável e, portanto, tangível.

A ideia de tangibilidade das formas culturais aparece de forma ainda mais instigante na antropologia cultural da circulação de Gaonkar e Povinelli (2003). Na defesa de um programa de análise cultural focado na materialidade das formas culturais na esfera pública, os autores ressaltam a necessidade de uma crítica que não sucumba à tentação de buscar o significado das formas, textos e eventos que se materializam no espaço social; mas sim situar os processos de circulação e transfiguração no qual esses objetos se tornam "palpáveis" e reconhecíveis. 0 desafio, para Gaonkar e Povinelli, é compreender a materialidade das formas que emergem dos movimentos globais de circulação e o que as torna reconhecíveis no contexto em que estão inseridas.

Movidos pela premissa de que formas culturais são vetores (móveis) do imaginário cultural e social, os autores utilizam os conceitos de circulação e transfiguração em substituição às ideias de significado e tradução. Propõem uma mudança radical de abordagem do fenômeno cultural a partir de uma mudança de foco: da leitura de textos sociais, arquivos e objetos para o estudo dos fluxos culturais globais. Entendem que as dinâmicas nacionais e transnacionais da vida pública não podem ser verdadeiramente apreendidas sem a compreensão dos fluxos e formas culturais de maneira integrada. Argumentam que a relação entre fluxos e formas leva inevitavelmente às dinâmicas da circulação:

5 " $[$...] ou mais precisamente ao que Benjamin Lee e Edward Li Puma (2002) chamam de culturas da circulação. Há um reconhecimento crescente da importância da circulação como uma matriz nas quais surgem e são reconhecidas as formas sociais, tanto textuais quanto temáticas. Isso é evidente no caso das três formas/ formações sociais características do imaginário social ocidental: a esfera pública, o estado cidadão e o mercado".
[...] or more precisely what Benjamin Lee and Edward LiPuma (2002) term cultures of circulation. There is a growing recognition of the importance of circulation as the enabling matrix within which social forms, both textual and topical, emerge and are recognizable when they emerge. This is evident in the case of the three self-reflexive social forms/formations characteristic of modern social imaginaries in the West: the public sphere, the citizen state, and the market ${ }^{5}$. (TAYLOR, 2002 apud GAONKAR; POVINELLI, 2003, p. 389)

Gaonkar e Povinelli (2003) retornam ao conceito de esfera pública de Habermas para apontar o momento fundador da crítica pública democrática na modernidade, baseada em novas formas de subjetividade e sociabilidade. Em autores como Habermas e Anderson e Urban a esfera pública se constitui na complexa interrelação entre instituições, formas textualizadas de subjetividade e discursos sobre essas formas. Subjetividades e sociabilidades dependem da circulação de formas textuais semióticas e materiais (livros, jornais, revistas, etc) a partir das quais os sujeitos se imaginam e se reconhecem no corpo social. Da mesma forma, estado e mercado corroboram para a constituição da esfera pública, atuando na construção de uma sociabilidade baseada na ideia de "stranger-sociability", a ação coletiva entre sujeitos que não se conhecem entre si - noção contemporânea de comunidades interpretativas e imaginários sociais.

Os autores ressaltam, ainda, que não é mais possível pensar em circulação como simples movimento de pessoas, mercadorias, ideias e imagens que se movem de um lugar para outro. Circulação torna-se um processo social com formas próprias de abstração, avaliação e limitação, criadas "pelas interações entre tipos específicos de formas de circulação e as comunidades interpretativas constituídas em torno deles" (LEE; LIPUMA, 2002, p. 192). Entendem que as comunidades de interpretação fundam novos protocolos de reconhecimento ao criarem formas 
e práticas culturais identificáveis, demarcando fronteiras baseadas em suas dinâmicas internas.

6 "Em uma determinada cultura de circulação, é mais importante seguir a proliferação e a coexistência de varias formas culturais/textuais, em todas as suas formas de mobilidade e mutabilidade, do que tentar delimitar a sua frágil autonomia e especificidade".
In a given culture of circulation, it is more important to track the proliferating co presence of varied textual/cultural forms in all their mobility and mutability than to attempt a delineation of their fragile autonomy and specificity ${ }^{6}$. (LEE; LIPUMA, 2002, p. 391-392)

O pressuposto teórico da circularidade serve à observação da diversificação de estilos e fragmentação de nichos mercadológicos abertos no campo da produção musical brasileira, a partir da década de 1980, quando começaram a ocupar espaço novas experiências musicais urbanas, como as diferentes vertentes do rock nacional, e regionais, como o brega romântico e o sertanejo. Tal processo de diversificação mercadológica vem aumentando exponencialmente, sobretudo a partir dos anos 2000 em decorrência do acesso às novas tecnologias de produção e circulação musicais, como atesta o tecnobrega. É nesse contexto de interação entre mercadorias musicais diversificadas que novos discursos de legitimação, em meio a embates ideológicos e estéticos, vêm gerando novas matrizes de reconhecimento público na esfera musical.

Deve-se ressaltar, ainda, que essa pluralidade de estilos evidencia processos de apropriação dos padrões da música pop mundial, seja ela periférica (no sentido do popular) ou não, que embaralham as noções de "lugar de origem", ainda que momentaneamente, e cristalizam a coexistência de mercadorias musicais que, embora formalmente distintas, se utilizam de códigos (referentes) comuns. É curioso observar como os hits internacionais, os sucessos de Madonna ou Beyoncé, por exemplo, ganham recriações no tecnobrega facilmente reconhecíveis, embora com todos os signos do seu localismo. Tensão que também se materializa nos elementos visuais dessa cena musical, incluindo figurinos, postura e performance dos artistas.

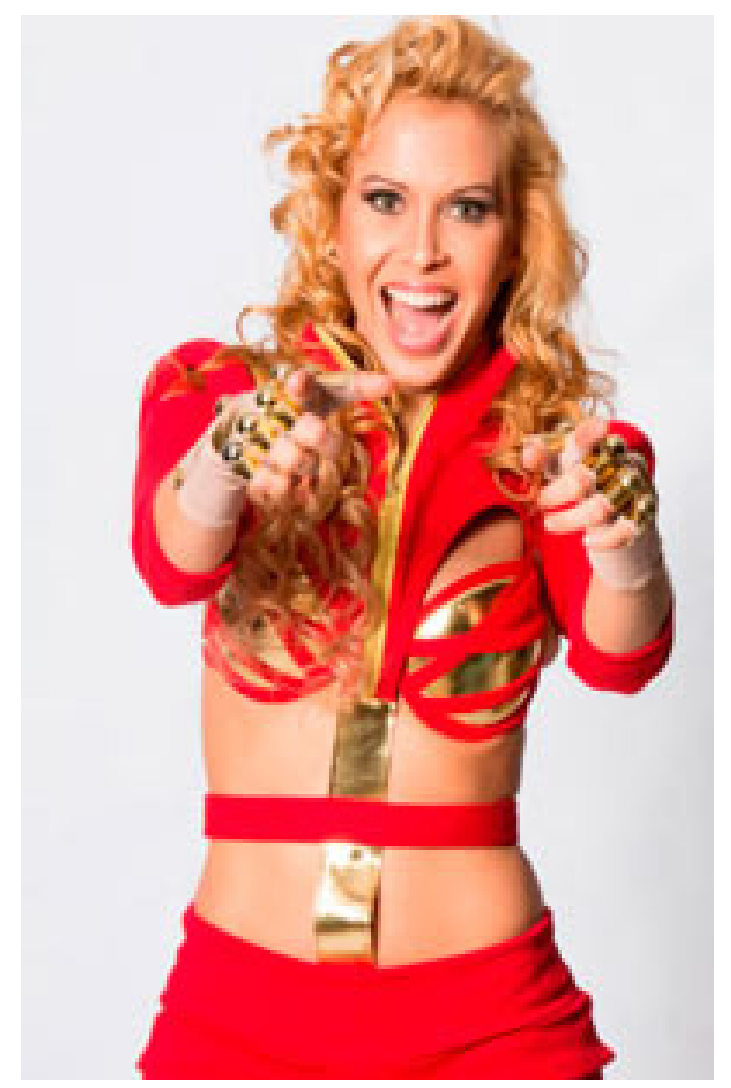

Figura 1: A cantora Joelma da Banda Calypso, há14 anos o maior case de sucesso do tecnobrega paraense, inspira veteranas e iniciantes (Foto cortesia da assessoria de imprensa da cantora) 


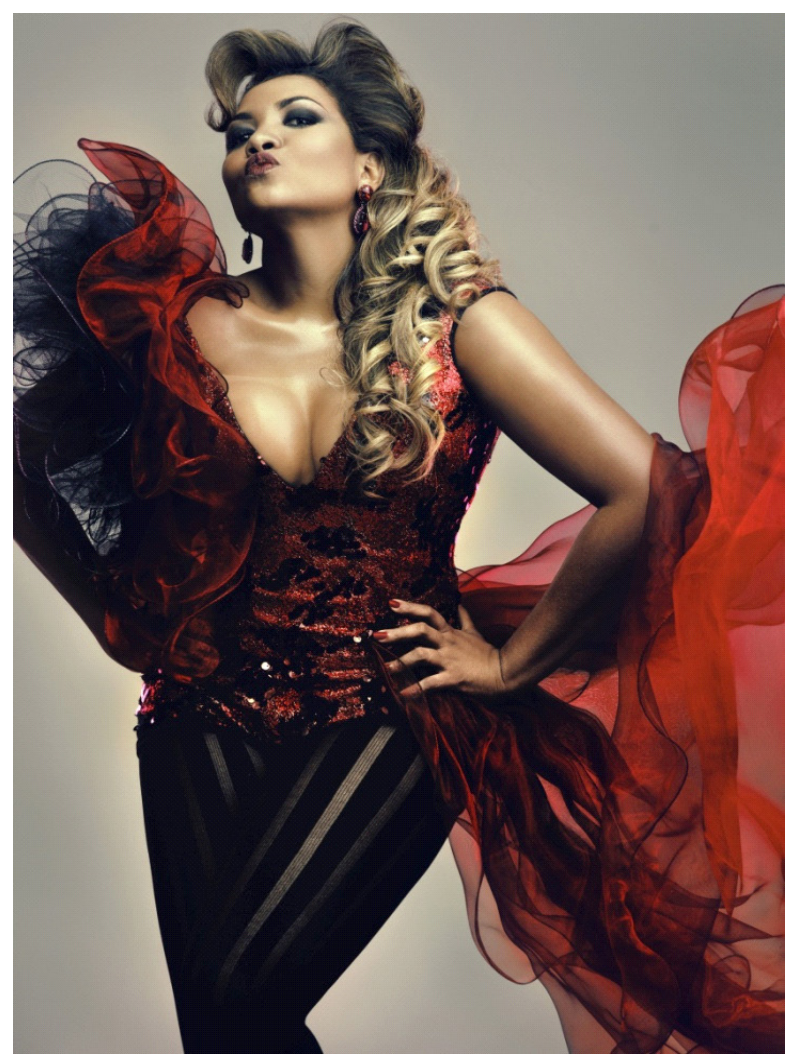

Figura 2: Gaby Amarantos incorpora figurinos e performances de estrelas do showbiz mundial sem abrir mão dos signos do seu localismo (Foto: cortesia de Junior Franch (Scarlae)/Assessoria de Imprensa Gaby Amarantos).

Ainda que a música brega tenha desempenhado papel de destaque no contexto da ampliação do mercado musical brasileiro, impulsionando os números da indústria fonográfica ao longo dos anos 1970, e que o crescimento do mercado nacional de bens simbólicos tenha sido vertical, as distinções entre o que é autêntico e cópia, ou entre o que é de bom gosto e mau gosto continuaram operando como lógica de segmentação criada pela própria indústria da música e alimentada pelos chamados "formadores de opinião". É elucidativa a contextualização feita por Freire Filho e Herschmann (2007) sobre as dificuldades e obstáculos enfrentados pelas expressões musicais brasileiras não canônicas a partir da expansão de uma cultura de origem popular, desenvolvida de maneira distinta dos modelos idealizados pelas vanguardas artísticas e intelectuais modernas. Os autores lembram que, à época, a crítica contrapunha a pureza de intenção dos gêneros "de raiz" ou a expressão desinteressada ou politicamente engajada dos artistas "autênticos" ao impulso mercenário de gravadoras e criadores e suas "criações, armações".

Nesse contexto, a diversificação de nichos mercadológicos, a partir de 1980, colocou em operação "um jogo contínuo de significados" (FREIRE FILHO, 2006, p. 31) na construção de valor da música popular produzida no país, ainda em função dos usos e motivações dos chamados grupos de status, como é o caso da música sertaneja, nos anos 1980, e do forró eletrônico, na década seguinte. No entanto, a hipótese defendida neste trabalho é de que, embora o processo de diferenciação social no julgamento de valor da música popular seja marcado historicamente por disputas de poder, a aceleração da circulação global das mercadorias musicais vem introduzindo um novo paradigma de valoração musical. Ideia que encontra eco no que a etnomusicóloga colombiana Ana Maria Ochoa Gautier (2006) descreve como "sonic turn", fenômeno que, segundo a autora, termina por redefinir a ideia de modernidade letrada na América Latina, desestabilizando a esfera pública musical mainstream.

Entre os fatores que teriam motivado essa "virada", Gautier aponta a proliferação de novos gêneros musicais populares, produzidos em estúdios locais que operam descolados 
da indústria institucional, e estabelecem novas políticas de produção e circulação musicais, como é o caso do tecnobrega. Aqui, a autora fala sobre estilos musicais

7 “[...] que historicamente não têm ligações com as políticas de base locais, servindo de agenda crucial para a constituição de práticas musicais que muitas vezes desafiam noções de pertencimento, herança ou resistência musicais. Músicas que não são nem 'jovens', nem 'folclóricas' nem facilmente associadas a movimentos sociais ou a estéticas revolucionárias, mas cujas mediações tecnológicas, formas de constituir identificações e localizações regionais desafiam, pelo menos no seu estágio inicial de consolidação, tipologias musicais ou associações fáceis." which historically have not been tied to place-based politics, serving as a crucial sonic agenda for the constitution of musical practices that often defy notions of musical belonging, heritage or resistance. Music that are neither "youth music" nor "folk", nor easily tied to either a social movement or a revolutionary aesthetic, but whose technological mediations, forms of construing identification and regional localizations defy, at least in their initial stages of consolidation, easy musical typologies or associations. [...] $]^{7}$ (GAUTIER,2006, p. 805-806)

Embora não fale especificamente sobre a materialidade das formas culturais, como o fazem Gaonkar e Povinelli, Ana Maria Ochoa Gautier enfatiza os processos de circulação de mercadorias musicais no contexto da globalização a partir da intensificação e diversificação dessa produção. Ressalte-se, mais uma vez, que a utilização de recursos tecnológicos na produção do tecnobrega sintoniza essa experiência musical com circuitos musicais periféricos do mundo, reafirmando uma circularidade que também se (retro)alimenta da produção de discursos globais (e locais) de legitimação. Deve-se lembrar que a recente noção de circularidade introduzida na análise cultural e na teoria da mídia focaliza a mobilidade das formas culturais em circulação no espaço social, e que, embora autores como Gaonkar, Povinelli, Benjamin Lee e Edward LiPuma não explorem especificamente a dimensão econômica dessa circularidade, entende-se que as dinâmicas do mercado têm papel preponderante nos processos de transfiguração e reconhecimento das mercadorias culturais.

\section{Políticas de reconhecimento}

O percurso de legitimação do tecnobrega, com base na análise de reportagens, entrevistas, resenhas e artigos publicados em jornais, revistas, sites e blogs (nacionais e internacionais), a uma primeira leitura, parece desestabilizar a ideia de construção de valor com base na distinção social do gosto. Discursos produzidos por jornalistas, críticos, artistas e intelectuais, de maneira geral, enfatizam a "inventividade", "vitalidade" e "energia" dessa expressão musical que, em boa parte dos textos, é apontada como uma espécie de resposta à crise fonográfica global. Aqui, o status de cult nacional conquistado pelo tecnobrega pode ser observado à luz do que Massumi e Manning (s.d.) chamam de produção do novo ("from good forms to new forms"), como se apreende das passagens reproduzidas abaixo:

O tecnobrega também oferece um modelo de negócio diferente que representa um significante desafio à tradicional cena musical. [...]. Os críticos dizem que o tecnobrega incentiva a tolerância à pirataria, que custa ao Brasil milhares de empregos e bilhões de dólares em impostos, mas os defensores do tecnobrega dizem que essa música oferece à indústria um caminho à frente. A lição número um deve ser a inovação - se você quer sobreviver na indústria musical agora você tem que inovar - diz Ronaldo Lemos, diretor do Creative Commons Brazil e professor na Escola de Direito da FGV [...]. Isto é um ponto muito importante que a indústria da música precisa aprender porque, se você olhar para os últimos dez anos verá que não tem havido muita inovação acontecendo na indústria da música. (DUFFY, 2009, s.p.)

Assim como a bossa nova, que além de um estilo musical se tornou um estado de espírito de uma época, o tecnobrega de Belém do Pará, mais do que uma música, criou um novo modelo de negócios na era digital [...]. O americano Chris Anderson, editor da revista Wired e autor do best-seller planetário The Long Tail, referência máxima para o presente das mídias digitais e para os 
modelos de negócio na internet, esteve em Belém no ano passado, mergulhou na novidade, e em seu novo livro dedicou um capitulo inteiro à revolução do tecnobrega - como modelo de negócios do século XXI [...]. O tecnobrega inovou instituindo a pirataria de si mesmo, como meio barato de popularizar artistas e fazer dinheiro com apresentações ao vivo [...]. Virou case internacional e um modelo de sucesso. (MOTA, 2008, s.p.)

Embora focados na observação de um fenômeno local, esses textos corroboram as discussões em torno das transformações em curso nas indústrias culturais globais, com ênfase na emergência de formas musicais geradoras de novos significados e identidades culturais, "novas culturas". Ou, nos termos de Urban (2001), em uma "metacultura" constituída a partir da elaboração discursiva de formas culturais em circulação. Gaonkar e Povinelli (2003) ressaltam que não há um modelo fixo de interpretação das formas culturais que se movem e se transfiguram na esfera pública, mas lembram que elas são reconhecidas como tais não apenas por conta das contingências ou da natureza material do seu signo, mas porque "They are bound by the analytic mode by which they are tracked" ["elas são vinculadas pela forma analítica por meio da qual fazem sentido"] [GAONKAR; POVINELLI, 2003, p. 388). Sob essa perspectiva, entende-se que a produção do conhecimento musical - aí também considerando aquele que circula na mídia ocupa lugar central na conformação da matriz a partir da qual formas sociais, textuais e tópicas relacionadas à música emergem e tomam forma.

O que está em questão para Gaonkar e Povinelli, antes dos vetores de significado e valor, são as relações de poder que se escondem por trás das políticas de transfiguração que produzem o reconhecimento das formas culturais como tais. Da mesma forma, a noção de circularidade desenvolvida neste artigo não passa à margem da observação do jogo ideológico do capital na construção de valor das mercadorias culturais - é a força da economia do tecnobrega, afinal, que lhe confere prestígio e reconhecimento-, mas as dinâmicas das culturas de circulação, na perspectiva aqui explorada, apontam para um processo de democratização, ou, ao menos, de desestabilização das hierarquias culturais na publicização de expressões historicamente situadas à margem do discurso cultural hegemônico, na medida que são disponibilizadas lado a lado com mercadorias musicais que emergem de outros contextos.

Parte-se aqui do pressuposto de que a circulação de formas culturais e os discursos produzidos em torno dessas formas - as formulações e/ou o conhecimento gerador de sentidos -, constituem a sua materialidade. Materialidade, nesse caso, remete ao que é perceptível, ao que é reconhecível pelos sujeitos no ambiente social, e o que, nos termos de Gaonkar e Povinelli (2003), constitui uma "etnografia das formas" - compreendida com base nos usos que os sujeitos fazem das mesmas. Aqui, nos apropriamos da noção de transfiguração de que tratam Gaonkar e Povinelli para observar os discursos de legitimação produzidos em torno do tecnobrega como resultado de uma mudança nos regimes de reconhecimento, a partir da qual a lógica de funcionamento dessa produção musical toma prevalência sobre o seu significado como estética musical.

Gaonkar e Povinelli propõem uma análise cultural que parta do pressuposto de que as matrizes generativas se encontram no espaço social, colocando em diálogo (e/ou em confronto) o reconhecimento público dessas formas culturais. Enfatizam que essas culturas da circulação demandam transfigurações na materialidade, inteligibilidade e reconhecimento dos textos, eventos e práticas, as quais garantem às formas culturais seus protocolos de movimento seguro (ou não) no espaço social. Os autores se indagam acerca das matrizes geradoras da validação ou recusa de determinada forma cultural, e propõem uma mudança nas políticas de reconhecimento das formas culturais em circulação. $\mathrm{O}$ que parece lançar luz sobre os discursos de validação das culturas periféricas "digitais". 
A mudança no regime de reconhecimento do tecnobrega, afinal, acontece em um momento de reestruturação das indústrias culturais globais no contexto da comoditização da economia, quando inovação e inventividade se tornam palavraschave para a dinâmica das novas relações de produção e circulação de bens culturais. A materialidade das formas culturais em circulação - o jogo semiótico das matrizes generativas de que falam Gaonkar e Povinelli - parece, à primeira vista, se opor à dimensão imaterial das mercadorias que, nessa fase de transição do capitalismo garante valor de mercado, por exemplo, as emoções e sensações das execuções musicais ao vivo (HERSCHMANN, 2007). Mas, na realidade, tratamse de processos simultâneos de "transfiguração" em operação no contexto do que muitos autores chamam de "nova economia". Retórica que encontra eco no discurso midiático:

Com a entrada hoje no ar do site Overmundo (www.overmundo.com.br), projeto encabeçado pelo antropólogo Hermano Vianna, o advogado Ronaldo Lemos dará mais um passo na sua batalha para mudar a economia da cultura no Brasil e no mundo. "Estamos à beira de uma grande transformação, uma explosão. E a hora é agora. Há uma janela de oportunidade que vai ser fechada a qualquer momento", empolga-se e angustia-se Lemos. (VIANNA, 2006, s.p.)

O vice-presidente artístico e de marketing da Sony Music, Alexandre Schiavo, aponta para o colapso do sistema fonográfico industrial, que se reflete em índices de desemprego que assolam executivos, funcionários e artistas. [...] $\mathrm{Na}$ ponta oposta à da indústria, despontam os artistas que já se lançaram desconhecendo o que era o padrão de contratos milionários e mordomias das últimas décadas. (REPORTAGEM LOCAL, 2003, s.p.)

A crise nas indústrias culturais, de maneira geral, e na fonográfica, especificamente, vem se agravando desde a década de 1990, com a emergência das chamadas novas tecnologias e a sua expansão e consolidação no século XXI (LEMOS; CASTRO, 2008). É notória a transformação pelas quais passaram as relações entre produtores e consumidores, públicos e artistas, com forte impacto no mercado global. No campo musical, ressalta-se o processo de fusão e concentração mercadológica com a drástica redução do casting das gravadoras, sobretudo dos nomes identificados com o local ou o regional, o que aprofundou "os gargalos da produção, reduziu a diversidade de produtos distribuídos e passou a investir, cada vez mais, em menos artistas" (LEMOS; CASTRO, 2008, p. 19). Para se ter uma ideia, a venda de CDs caiu de 94 milhões de unidades, em 2000, para 52,9 milhões em 2005 (segundo dados da Associação Brasileira de Produtores de Discos - ABPD). O que, em certa medida, contribuiu para a formação de redes independentes de produção e circulação de mercadorias culturais baseadas nas tecnologias digitais.

No contexto da nova lógica de produção musical, a trajetória de legitimação do tecnobrega na esfera pública não é um fenômeno isolado. O localismo dessa música se articula com experiências musicais urbano-periféricas ao redor do Globo, cujas práticas criativas se originam em um cotidiano de exclusão sociocultural e na apropriação de ferramentas tecnológicas. Nesse cenário, sob o lastro teórico explorado neste artigo, é possível afirmar que o tecnobrega circula, ao mesmo tempo, como uma música que atualiza uma tradição musical típica da região Norte do Brasil, movida por suas próprias singularidades; e como uma música que está em total sintonia com as novas dinâmicas de produção musical praticadas em escala global, o que impacta na construção de valor e significado dessa cena musical no contexto periférico e global. Como lembra Will Straw, a materialidade das formas culturais em circulação acionam mecanismos de operação que conduzem a novas perspectivas de abordagem desses objetos: 
8 "O melhor argumento contra Bourdieu, sem dúvida, não é que as pessoas estão fazendo coisas com as imagens diferente daquilo que presume sua agonística, mas que as imagens estão fazendo coisas por elas mesmas através de caminhos complexos nos quais a sua circulação social as vincula aos lugares, objetos e conjuntos de sentidos".
The best argument against Bourdieu, arguably, is not that people are doing things with images other than those his agonistics presumes, but that images are doing things "on their on", through the complex ways in which their social circulation binds them to places, objects and clusters of sense ${ }^{8}$. (STRAW, 2009, p. 7)

Trata-se de uma mudança de paradigma que pode explicar a receptividade à produção de novas experiências musicais periféricas, reafirmando o distanciamento das práticas de apreensão centradas na modernidade tardia, colocada em xeque por Gautier (2006). Para a autora, no nível epistemológico, a análise musical atravessa hoje múltiplos processos de textualização e recontextualização, que ela descreve como "transculturation", ou seja, uma ampla reestruturação das noções de práticas, modos de significação e circulação da música produzida no mundo a rearticulação da relação entre o local, o nacional e o global, com base na intensificação de uma esfera transnacional.

Seguindo a proposição metodológica de Dillip Gaonkar e Elizabeth Povinelli (2003) baseada em processos de "transfiguração" e a noção de uma epistemologia da "transculturação" defendida por Ana Maria Ochoa Gautier (2006), afirma-se aqui que a construção de discursos de legitimação em torno da cadeia produtiva do tecnobrega pode ser apreendida como reflexo das políticas globais de circulação das mercadorias musicais no contexto de reestruturação da economia, com base na mediação tecnológica e no elogio da inventividade. Se não intervém diretamente na constituição de um conhecimento musical baseado na (re) produção de diferenciações sociais, tal abordagem parece mover, talvez apenas momentaneamente, o foco de análise para as dinâmicas de circulação das formas culturais cuja validação depende de sua própria materialidade.

\section{Considerações finais}

A análise da cena paraense do tecnobrega é um testemunho da existência de uma "nova esfera pública musical" (GAUTIER, 2006), relacionada tanto ao aumento da circulação do acervo musical produzido globalmente, quanto à acessibilidade das ferramentas tecnológicas que possibilitam autonomia de criação e de distribuição. Os discursos midiáticos de legitimação da música produzida na periferia de Belém estão em sintonia com o reconhecimento do poder de comunicação das culturas periféricas digitalizas e do fenômeno econômico que as mesmas protagonizam, evidenciando o lugar da informalidade nas "novas" indústrias culturais globais. A análise do tecnobrega é especialmente relevante nesse contexto, considerando tratar-se de um estilo musical que, apesar de gestado sem o aval de gravadoras ou de conglomerados midiáticos, está longe do underground cultural frequentemente positivado em suas representações. O tecnobrega, afinal, ainda é uma música socialmente estigmatizada.

A perspectiva defendida neste texto é a de que a percepção de uma "nova esfera pública musical" não equivale à afirmação da diluição completa das distinções valorativas historicamente constituídas, mas de uma abertura nos modos de apreensão da música popular em circulação. $O$ que parece relevante na hipótese de reconfiguração do paradigma crítico é a sua conexão com as "culturas da circulação" que, a partir da inter-relação de objetos culturais no espaço social de diálogo ou de confronto -, criam matrizes de reconhecimento público com base nos contextos globais nos quais estão inseridos, a partir das quais os sujeitos os validam ou recusam. São critérios de julgamento abertos e em permanente processo de "transfiguração", nos termos de Gaonkar e Povinelli (2003), e/ou "recontextualização" (GAUTIER, 2006).

Ganham força as construções discursivas que relacionam "invenção" e tecnologia, processos criativos e interação, criatividade e autonomia econômica. Assim, a afirmação de uma mudança no padrão de reconhecimento da música brega - do tecnobrega, especificamente - deve ser entendida no contexto de 
reestruturação das indústrias culturais globais, da comoditização da economia da cultura (HERSCHMANN, 2007) e da emergência de novas relações de produção e circulação de bens culturais.

\section{Referências Bibliográficas}

BARROS, L. G. Tecnobrega: A legitimação de um estilo musical estigmatizado no contexto do novo paradigma da crítica musical. 226f. Tese (Doutorado em Comunicação e Cultura) - Universidade Federal de Pernambuco, Pernambuco, 2011.

BOURDIEU, P. A distinção - crítica social do julgamento. São Paulo: Universidade de São Paulo, 2006.

CARDOSO, D. Festival tecno melody Brasil - aparelhagem "Super Pop", leva o povo ao delírio. Disponível em: <http://www.youtube.com/watch?v=XcwMNBaNtNw>. Acesso em: 19 ago. 2013.

DUFFY, G. Tecnobrega Beat Rocks Brazil. BBC News, Click. Disponível em: <http:// news.bbc.co.uk/2/hi/programmes/click_online/7872316.stm>. Acesso em: $20 \mathrm{de}$ abril de 2013.

ECO, U. A estrutura do mau gosto. In: Apocalípticos e integrados. 5. ed. São Paulo: Perspectiva, p. 69-128, 1998.

FREIRE FILHO, J. Moda, estilo de vida e distinção social: quando o brega vira fashion. In:VILLAÇA, N.; CASTILHO, K. (Orgs). Plugados na moda. São Paulo: Anhembi Morumbi, 2006.

FREIRE FILHO, J.; HERSCHMANN, M. (Orgs). Novos rumos da cultura da mídia, indústria, produtos, audiência. Rio de Janeiro: Mauad Editora, 2007.

GAONKAR, D.; POVINELLI, E. Technologies of Public Forms: Circulation, Transfiguration, Recognition. Public Culture, v. 15, n. 3, p. 385-397, 2003.

GAUTIER, A. M. O. Sonic Transculturation, Epistemologies of Purification and the Aural Public Sphere in Latin America. Social Identities, v. 12, n. 6, p. 803-825, 2006.

GUATARRI, F. Caosmose: um novo paradigma estético. São Paulo: Editora 34, 1995.

GUERREIRO DO AMARAL, P. M. Estigma e cosmopolitismo na constituição de uma música popular urbana de periferia: Etnografia da produção do tecnobrega em Belém do Pará. 242f. Tese (Doutorado em Musicologia/Etnomusicologia) Universidade Federal do Rio Grande do Sul, Rio Grande do Sul, 2009.

HERSCHMANN, M. Alguns apontamentos sobre a reestruturação da indústria da música. In: FREIRE FILHO, J.; HERSCHMANN, M. (Orgs.). Novos rumos da cultura da mídia. Rio de Janeiro: Mauad Editora, p. 161-168, 2007.

LEMOS, R.; CASTRO, O. Tecnobrega. O Pará reinventando o negócio da música. Rio de Janeiro: Aeroplano Editora e Consultoria, 2008.

LEE, B.; LI PUMA, E. Cultures of Circulation: The Imaginations of Modernity. Public Culture, v. 14, n. 1, p. 191-213, 2002.

MANNING, E.; MASSUMI, B. Technologies of Lived Abstraction. Disponível em: $<$ http://erinmovement.com/erin_manning.html>. Acesso em: 20 abr. 2013. 
MOTA, N. The tecnobrega revolution. Disponível em: <http://oglobo.globo. $\mathrm{com} /$ pais/moreno/posts/2008/11/21/the-tecnobrega-revolution-141751.asp>. Acesso em: 13 jul. 2013.

OPEN BUSINESS MODELS - Latin America \& Caribbean. Disponível em: <http:// openbusinesslatinamerica.org/sobre/>. Acesso em: 4 mar. 2012.

PEREIRA DE SÁ, S. Música eletrônica e tecnologia: reconfigurando a discotecagem. Disponível em: <http://textoslabcult.files.wordpress.com/2007/10/sa-simonepereira-musica-eletronica-e-tecnologia-reconfigurando-a-discotecagem.PDF>. Acesso em: 15 ago. 2010.

REPORTAGEM LOCAL. Artistas enxergam internet como aliada. Disponível em: <http://www1.folha.uol.com.br/fsp/ilustrad/fq2312200308.htm.> Acesso em: 11 jan. 2007.

STRAW, W. Systems of Articulation, Logic of Chance: Scenes and Communities in Popular Music. Cultural Studies, v. 5, n. 3, p. 368-388, 1991.

. The circulatory turn. In: CROW, B.; LONGFORD, M.; SAWCHUK, K. (Eds.). The Wireless Spectrum: The Politics, Practices and Poetics of Mobile Media. Toronto: University of Toronto Press (Digital Future Series), 2009.

TAGG, P. Introductory Notes to Semiotics of Music. Disponível em: <http://tagg. org/xpdfs/semiotug.pdf>. Acesso em: 11 jul. 2007.

TATIT, L. Todos entoam. São Paulo: Publifolha, 2007.

URBAN, G. Metaculture: how culture moves through the world. Minneapolis: University of Minnesota Press, 2001.

VIANNA, H. Central da periferia. Texto de Divulgação Disponível em: <http:// www.overmundo.com.br\%2Fdownload_banco\%2Fcentral-da-periferia-texto-dedivulgacao\&ei=Nzn9UdSPKJS89gTi7oHYDA\&usg=AFQjCNFGD1moc5KOUGMa4xL vTBYYt_yDNQ\&bvm=bv.50165853>. Acesso em: 11 jul. 2013.

Site amplia discussão sobre liberação de direito autoral. Disponível em: <http://www1.folha.uol.com.br/fsp/ilustrad/fq0603200612.htm>. Acesso em: 11 jul.2007 